\title{
BMJ Open Genetic associations between genes in the renin-angiotensin-aldosterone system and renal disease: a systematic review and meta-analysis
}

\author{
Laura Jane Smyth, ${ }^{\oplus 1}$ Marisa Cañadas-Garre, ${ }^{1}$ Ruaidhri C Cappa, ${ }^{1}$ \\ Alexander P Maxwell, ${ }^{1,2}$ Amy Jayne McKnight ${ }^{1}$
}

To cite: Smyth LJ, CañadasGarre M, Cappa RC, et al. Genetic associations between genes in the renin-angiotensinaldosterone system and renal disease: a systematic review and meta-analysis. BMJ Open 2019;9:e026777. doi:10.1136/ bmjopen-2018-026777

- Prepublication history and additional material for this paper are available online. To view these files, please visit the journal online (http://dx.doi org/10.1136/bmjopen-2018026777).

Received 19 September 2018 Revised 28 January 2019 Accepted 27 March 2019
Check for updates

(c) Author(s) (or their employer(s)) 2019. Re-use permitted under CC BY. Published by BMJ.

${ }^{1}$ Epidemiology and Public Health Research Group, Queen's University Belfast Centre for Public Health, Belfast, UK

${ }^{2}$ Regional Nephrology Unit, Belfast City Hospital, Belfast, UK

Correspondence to

Dr Laura Jane Smyth;

laura.smyth@qub.ac.uk

\section{ABSTRACT}

Background Chronic kidney disease (CKD) is defined by abnormalities in kidney structure and/or function present for more than 3 months. Worldwide, both the incidence and prevalence rates of CKD are increasing. The reninangiotensin-aldosterone system (RAAS) regulates fluid and electrolyte balance through the kidney. RAAS activation is associated with hypertension, which is directly implicated in causation and progression of CKD. RAAS blockade, using drugs targeting individual RAAS mediators and receptors, has proven to be renoprotective.

Objectives To assess genomic variants present within RAAS genes, ACE, ACE2, AGT, AGTR1, AGTR2 and REN, for association with CKD.

Design and data sources A systematic review and meta-analysis of observational research was performed to evaluate the RAAS gene polymorphisms in CKD using both PubMed and Web of Science databases with publication date between the inception of each database and 31 December 2018. Eligible articles included case-control studies of a defined kidney disease and included genotype counts.

Eligibility criteria Any paper was removed from the analysis if it was not written in English or Spanish, was a non-human study, was a paediatric study, was not a casecontrol study, did not have a renal disease phenotype, did not include data for the genes, was a gene expressionbased study or had a pharmaceutical drug focus.

Results A total of 3531 studies were identified, 114 of which met the inclusion criteria. Genetic variants reported in at least three independent publications for populations with the same ethnicity were determined and quantitative analyses performed. Three variants returned significant results in populations with different ethnicities at $p<0.05$ : ACE insertion, AGT rs699-T allele and AGTR1 rs5186-A allele; each variant was associated with a reduced risk of CKD development.

Conclusions Further biological pathway and functional analyses of the RAAS gene polymorphisms will help define how variation in components of the RAAS pathway contributes to CKD.

\section{INTRODUCTION}

Chronic kidney disease (CKD) is defined as a progressive loss of renal function measured
Strengths and limitations of this study

- Individuals with microalbuminuria were excluded from both the case and control definitions to improve the discrimination between individuals with and without renal disease as microalbuminuria may regress, remain stable or progress to macroalbuminuria.

- Due to previously reported heterogeneity between different ethnic groups, we included this as a risk factor and performed each analysis per ethnicity.

- Some studies in our search could not be included in quantitative analysis as they lacked information relating to genotype counts and had an unclear measure and definition of albuminuria for both cases and controls.

as a reduction in glomerular filtration rate (GFR) to $<60 \mathrm{~mL} / \mathrm{min} / 1.73 \mathrm{~m}^{2}$, or the presence of persistent urinary abnormalities including albuminuria and/or structural alterations which have been present for at least 3 months. ${ }^{1}$ CKD is an increasing public health issue given its associated morbidities, premature mortality and management of advanced CKD is a significant burden on healthcare budgets worldwide. ${ }^{2}{ }^{3}$ There is substantial evidence that inherited genetic variants, ${ }^{4}$ the presence of diabetes ${ }^{5}$ or hypertension $^{6}$ and an individual's ethnicity ${ }^{7} 8$ directly influence the development of various CKD phenotypes.

The renin-angiotensin-aldosterone system (RAAS) is a homeostatic endocrine system which is of critical importance to the regulation of blood pressure and maintenance of fluid and electrolyte balance. ${ }^{9} 10$ Renin (REN), secreted from the juxtaglomerular apparatus in response to reduced renal perfusion pressure, catalyses the conversion of angiotensinogen (AGT) to angiotensin I. ${ }^{11}$ Subsequently, angiotensin I converting 
enzyme $(A C E)$ cleaves angiotensin I to generate angiotensin II, which regulates heart and kidney function by binding to and activating angiotensin II receptors (type I and type II). ${ }^{11} 12$ The angiotensin II type I receptors are responsible for multiple biological actions of RAAS including vasoconstriction and sodium reabsorption. ${ }^{11-14}$

Increased RAAS activation is linked to progression of CKD of different aetiologies, especially diabetic nephropathy (DN) ${ }^{11}{ }^{15-18}$ and is mediated by hypertensive injury ${ }^{17}$ and accelerated renal fibrosis. ${ }^{19}$ The physiological relevance of this pathway in the progression of CKD has focused attention on RAAS components including $A C E$, ACE2, AGT, angiotensin II receptor type 1 (AGTR1), angiotensin II receptor type 2 (AGTR2) and renin (REN), as candidate genes for various CKD-related phenotypes. Multiple studies have implicated RAAS gene variants in the progression of CKD..$^{20-26}$

This manuscript describes a systematic review and meta-analysis to examine published data reporting genetic variants present within six of the RAAS candidate genes: ACE, ACE2, AGT, AGTR1, AGTR2 and REN, for a range of CKD phenotypes and ethnicities, to help define their putative roles as risk factors for CKD.

\section{METHODS}

\section{Search strategy}

A systematic search was undertaken following recognised methods, the Meta-analysis of Observational Studies in Epidemiology (MOOSE) guidelines,${ }^{27}$ by two investigators. PubMed and Web of Science online databases were searched for studies published between the inception of each database and 31 December 2018. All search terms are detailed in online supplementary table S1.

The general strategy of the searches was to follow the structure: (all alternative versions of each gene name, separated by the Boolean operator OR) AND (kidney OR nephrology OR nephropathy OR renal) AND (SNP OR polymorphism OR variant OR allele OR genotype). For each search term, where an appropriate Medical Subject Headings (MeSH) term was available, the query included the quoted search term OR the MeSH term. Additional filters including English OR Spanish languages, human studies, case-control studies, not clinical trials, not review articles, not a case report and not a meta-analysis were applied.

Reference lists from included publications were also manually searched. Two authors (LJS and MCG) independently conducted the literature search, screened the articles and extracted the data. In the case of any disagreement, a third author (RCC) considered the articles. A range of CKD phenotypes were included in this analysis, the case and control definitions are included in table 1.

\section{Inclusion/exclusion criteria}

Inclusion criteria were judged against a standardised list of agreed criteria (LJS, MCG and AJM), where the English or Spanish language publication described an
Table 1 Phenotypic comparisons included in this analysis

\begin{tabular}{|c|c|}
\hline Case group & Control group \\
\hline $\begin{array}{l}\text { Autosomal dominant polycystic kidney } \\
\text { disease }\end{array}$ & Healthy controls \\
\hline Atherosclerotic renal artery stenosis & Healthy controls \\
\hline Balkan endemic nephropathy & Healthy controls \\
\hline Chronic glomerulonephritis & Healthy controls \\
\hline Chronic kidney disease & Healthy controls \\
\hline Diabetic nephropathy* & Diabetes mellitus \\
\hline Diabetic nephropathy ${ }^{*}$ & Healthy controls \\
\hline End-stage renal disease & Healthy controls \\
\hline End-stage renal disease & Type 1 diabetes mellitus \\
\hline Focal segmental glomerulosclerosis & Healthy controls \\
\hline Glomerulonephritis & Healthy controls \\
\hline Hypertension-related renal disease & $\begin{array}{l}\text { Healthy controls with } \\
\text { hypertension }\end{array}$ \\
\hline Hypertension-related renal disease & Healthy controls \\
\hline IgA nephropathy & Healthy controls \\
\hline Interstitial nephritis & Healthy controls \\
\hline Lupus nephritis & $\begin{array}{l}\text { Systemic lupus } \\
\text { erythematosus }\end{array}$ \\
\hline Lupus nephritis & Healthy controls \\
\hline Minimal change nephrotic syndrome & Healthy controls \\
\hline Non-Balkan endemic nephropathy & Healthy controls \\
\hline Nephroangiosclerosis & Healthy controls \\
\hline Polycystic kidney disease & Healthy controls \\
\hline Primary membranous glomerulonephritis & Healthy controls \\
\hline Primary membranous glomerulonephritis & Organ donors \\
\hline Renal transplant recipients & Healthy controls \\
\hline Renal transplant recipients & Kidney donors \\
\hline Type 1 diabetic nephropathy* & Type 1 diabetes mellitus \\
\hline $\begin{array}{l}\text { Type } 1 \text { diabetic nephropathy linked to } \\
\text { end-stage renal disease }\end{array}$ & Healthy controls \\
\hline $\begin{array}{l}\text { Type } 1 \text { diabetic nephropathy linked to } \\
\text { end-stage renal disease }\end{array}$ & Type 1 diabetes mellitus \\
\hline Type 2 diabetic nephropathy & Type 2 diabetes mellitus \\
\hline $\begin{array}{l}\text { Type } 2 \text { diabetic nephropathy linked to } \\
\text { end-stage renal disease }\end{array}$ & Healthy controls \\
\hline $\begin{array}{l}\text { Type } 2 \text { diabetic nephropathy linked to } \\
\text { end-stage renal disease }\end{array}$ & Type 2 diabetes mellitus \\
\hline
\end{tabular}

*In the studies including diabetic nephropathy as cases, only individuals with reported macroalbuminuria or proteinuria were included. Individuals with microalbuminuria were excluded.

adult, human case-control study of a defined kidney disease. In the rare instances when suspected duplicate data were identified within two or more included articles, only the article either published first, or that with the larger number of participants was included.

Articles were excluded if they included paediatric subjects, were a pharmacological-based study reporting clinical trials of medications, did not contain genotypic data for the correct gene or were non-human studies. 


\section{Data extraction}

Where available, the size of each study, case group disease definition and number of individuals, control group definition and number of individuals, ethnicity, genetic variant, genotype in the format of allele 1-heterozygoteallele 2 and allele counts were recorded and calculated in spreadsheets by two authors (LJS and MCG). Articles were reassessed where any disagreement occurred and a third reviewer was employed. Ethnicities were recorded from the articles and recoded following the International Genome Sample Resources' online guidance. ${ }^{28}$ Where any population did not align to a listed population code, a new one was created for the purposes of this study. All ethnicity codes are available in online supplementary table S2. The data collected were divided into disease phenotype groups to ensure a high level of homogeneity.

\section{Statistical analysis}

Each genetic variant which had been investigated and reported in at least three independent publications for the same ethnicity and phenotype was included in quantitative statistical analyses. Review Manager (RevMan V.5.3) (The Cochrane Collaboration, The Nordic Cochrane Centre, Copenhagen, Denmark) was employed to facilitate the analysis of allele frequencies. For each single nucleotide polymorphism (SNP), the total number of alleles was recorded per case and control group. Hardy-Weinberg equilibrium was calculated for all included studies, for cases and controls separately. Statistical analyses were performed using the random-effects model as heterogeneity was expected. For each SNP, this analysis provided the $\mathrm{p}$ value, OR and $95 \%$ CIs. It also facilitated the assessment of the heterogeneity level using the $\mathrm{I}^{2}$ statistic. ${ }^{29}$ Forest plots and funnel plots were generated automatically to assess publication bias and the significance value was set at $\mathrm{p}<0.05$ (LJS and RCC).

The genotyping quality of the studies was assessed by reported genotype completion rate and Hardy-Weinberg equilibrium. Phenotypes included in this analysis are shown in table 1; individuals with microalbuminuria were excluded alongside the studies that focused on disease progression. No sensitivity analysis was performed. All study methodologies conformed to the MOOSE criteria. ${ }^{27}$ No published protocol is available for this review. The workflow followed a consistent pattern for each gene. A summary of this is included in figure 1 .

\section{Patient and public involvement}

Neither patients nor the public were directly involved in the design of this study, which analysed previously published data available in the public domain.

\section{RESULTS}

The database searches returned 3531 results, 144 of which remained following the application of inclusion and exclusion criteria and the removal of any SNP which was not reported on at least three occasions.
Several articles included data for more than one gene, signifying that they have emerged multiple times throughout the database searches; the total number of individual articles was therefore 114 . The search strategies are included as online supplementary figure S1A-F. All excluded studies are listed in online supplementary table S3A-F.

The total number of subjects analysed within these studies $(\mathrm{n}=114)$ was 18231 individuals with renal disease and 21887 individuals acting as controls. For SNPs in three of the RAAS genes, ACE2, AGTR2 and REN, there were less than three independent populations studied. A summary table detailing the main results is included as table 2.

\section{Angiotensin converting enzyme}

A total of 15 quantitative analyses were completed for the insertion/deletion (I/D) polymorphism located within $A C E$ in eight phenotypes, details of which are included in online supplementary table S4. Three quantitative analyses returned a significant result. The first analysis comprised 11 publications, each studying an East Asian population with type 2 diabetes and nephropathy (T2DN) and compared with type 2 diabetes mellitus without nephropathy (T2DM). Figure 2A displays these results, $\mathrm{p}=0.009$; OR $0.74 ; 95 \%$ CI 0.59 to $0.93, \mathrm{I}^{2}=55 \%$, showing that the presence of the insertion variant at this $A C E$ locus was significantly associated with this phenotype. The insertion provides a lower risk of developing T2DN in an East Asian population as demonstrated in five studies, which contributed to $51.5 \%$ of the weight in this analysis. Figure 2B shows the associated funnel plot for this analysis.

The $A C E$ insertion variant was similarly significantly associated with a lower risk of T2DN compared with T2DM in a South Asian population, despite the presence of a high level of heterogeneity ( $\mathrm{p}=0.01$; OR $0.57 ; 95 \%$ CI 0.37 to $0.87 ; \mathrm{I}^{2}=89 \%$ ). This was consistent with the direction of effect in four studies, which contributed to $67.7 \%$ of the weight in this analysis (figure 2C). The funnel plot for this analysis is displayed within figure 2D.

The comparison of East Asian individuals with end-stage renal disease (ESRD) compared to a healthy population with no evidence of renal disease also showed a significant association with moderate levels of heterogeneity ( $\mathrm{p}=0.08$; OR $0.8 ; 95 \%$ CI 0.67 to $0.94 ; \mathrm{I}^{2} 68 \%$ ). Four studies, supporting $69.7 \%$ of the weight in the analysis had shown this effect (figure 2e). Figure $2 \mathrm{f}$ shows the associated funnel plot for this analysis.

In each analysis (T2DN vs T2DM; end-stage renal disease [ESRD] vs normal), the presence of the $A C E$ insertion was associated with a lower risk of developing the CKD phenotype in the respective populations. The non-significant forest plots are included in online supplementary figure S2A-I and the associated funnel plots within online supplementary figure S3A-I. 


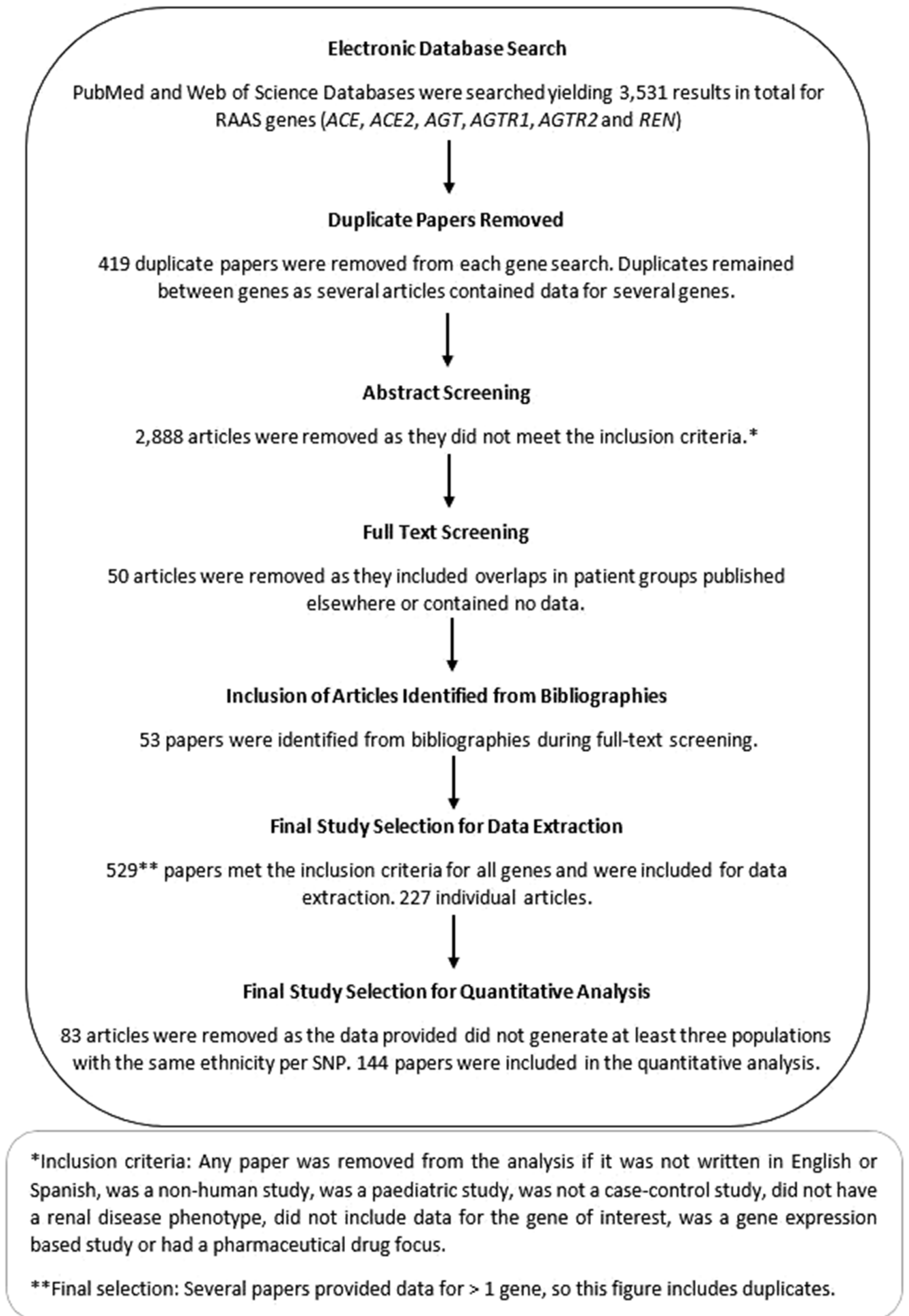

Figure 1 Workflow pattern. RAAS, renin-angiotensin-aldosterone system; SNP, single nucleotide polymorphism.

\section{Angiotensinogen}

Seven quantitative analyses were completed for rs699, where the $\mathrm{T}$ allele was compared with the $\mathrm{C}$ allele. Details of each of these comparisons are included in online supplementary table S5. One significant result was identified-the comparison of ESRD with healthy controls in a European population. The results were $\left(\mathrm{p}=0.002 ;\right.$ OR $0.84 ; 95 \%$ CI 0.76 to $\left.0.94 ; \mathrm{I}^{2}=0 \%\right)$ and are shown in figure 2G. Only the study with population size over 2000 patients, supporting $46.2 \%$ of the weight in the meta-analysis, had achieved significance with the original figures. These results indicate that the presence of the $\mathrm{T}$ allele is associated with a lower risk of developing ESRD in this population. The funnel plot for this analysis is displayed within figure $2 \mathrm{H}$. The forest plots containing the non-significant results are included in 


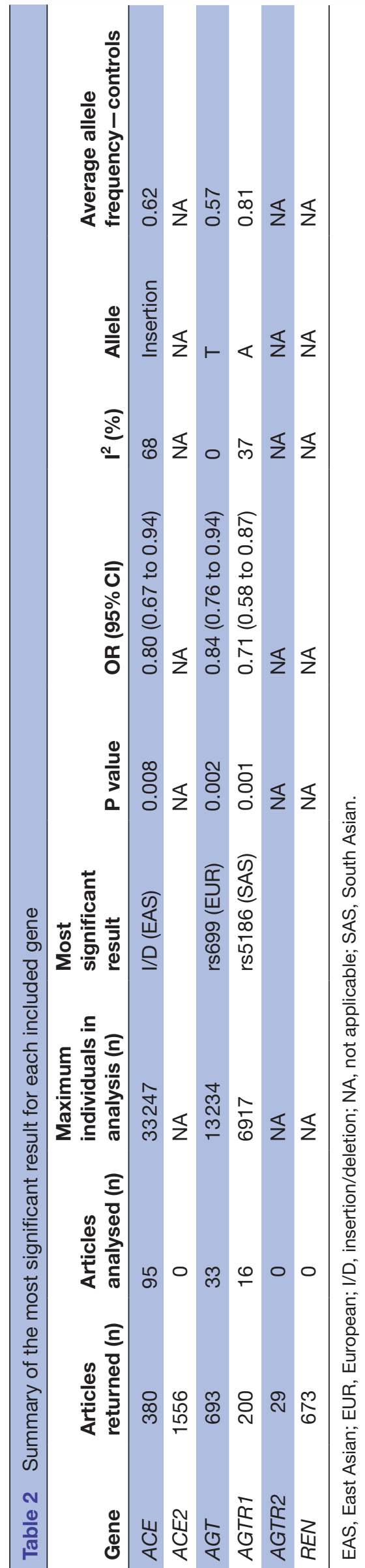

online supplementary figure S4A-F, and the associated funnel plots within online supplementary figure S5A-F.

\section{Angiotensin II receptor type 1}

Four quantitative analyses were performed for AGTR1 rs5186, comparing the A allele with the C. Details of these comparisons are included within online supplementary table S6. One of the four studies returned a significant result for association, the comparison of T2DN with T2DM in a South Asian population ( $\mathrm{p}=0.001$; OR 0.71; $95 \%$ CI 0.58 to $0.87 ; \mathrm{I}^{2}=37 \%$ ). This result resembled the findings of two of the three studies which contributed $87 \%$ of the weight in the meta-analysis, as shown in figure 2I. Figure 2J contains the associated funnel plot. These results indicate that the presence of the A allele is associated with a lower risk of developing T2DN in this population. The non-significant results in forest plot format are included in online supplementary figure $\mathrm{S} 6 \mathrm{~A}-\mathrm{C}$ and in funnel plot format within online supplementary figure S7A-C.

Studies not complying with Hardy-Weinberg equilibrium are shown in online supplementary table S7. Allele frequencies for healthy control populations included in this analysis were assessed. None showed signs of bias in any included study, in comparison to all available dbSNP reported frequencies as shown in online supplementary file $\mathrm{S} 1$.

\section{DISCUSSION}

Investigations into RAAS genetic variants previously reported to have been associated with a range of CKD phenotypes were undertaken. A total of 3531 studies were identified, 114 of which met the inclusion criteria. Subsequently, 26 quantitative analyses were completed for three RAAS genes where there were at least three independent population studies of the RAAS gene variants. Five significant results within three genes were obtained at the significance level $\mathrm{p}<0.05$, each revealing an association with CKD.

$A C E$ is encoded by $D C P 1$ and is a key component of the RAAS. It catalyses the modification of angiotensin I to II, which is more biologically active. ${ }^{30} A C E$ is the most frequently studied gene of the RAAS. ${ }^{31}$ First sequenced in $1992,{ }^{32}$ this $287 \mathrm{bp}$ Alu repetitive element at intron $16^{32}$ is located on chromosome 17 and is represented by four individual SNPs: rs4646994, rs1799752, rs4340 and rs13447447. Further understanding of its genetic architecture and disease associations may enable patient groups to benefit from targeted therapies with ACE inhibitors. ${ }^{33}$

Since 1994, the association of $A C E$ and DN has been rigorously investigated, ${ }^{33} 34$ with studies returning conflicting results. A meta-analysis undertaken in 2005 by $\mathrm{Ng}$ and colleagues ${ }^{35}$ reported a statistically significant result wherein the $A C E$ insertion was associated with protection from development of DN in Asians and Caucasians. A second meta-analysis undertaken in 2012 also identified an association between the $A C E \mathrm{I} / \mathrm{D}$ 
A

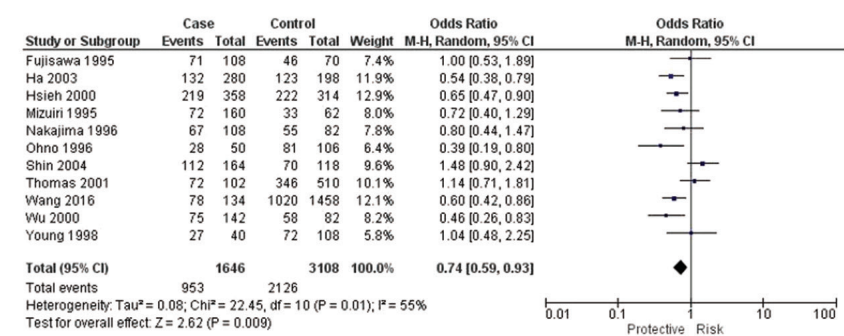

C

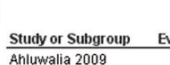
Ahluwalia 2009 Kumar 2013
Mowa 2007 Naresh 2009 Rozeena 2012 Vishwanathan 200 otal $(95 \% \mathrm{C}$

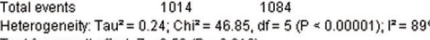

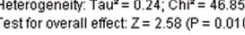

E

Case Control
Odds Ratio

$\begin{array}{llrlrl}152 & 480 & 215 & 510 & 18.6 \% & 0.64[0.49,0.83]\end{array}$

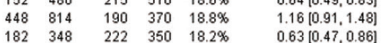
$\begin{array}{rrrrrr}182 & 348 & 222 & 350 & 18.2 \% & 0.63[0.47 .0 .86] \\ 19 & 60 & 35 & 60 & 12.4 \% & 0.33[0.16,0.70]\end{array}$ $\begin{array}{llllll}134 & 336 & 394 & 592 & 18.5 \%\end{array}$ $172 \quad 28 \quad 46 \quad 135 \%$ $0.55[0.28,1.00$ $0.57[0.37,0.87]$

\section{Protective Risk} Odds Ratio
M.H, Random, $95 \% \mathrm{Cl}$

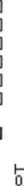

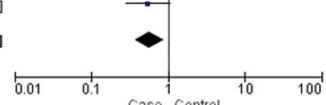

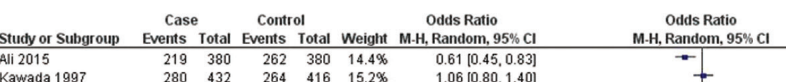
$\begin{array}{lllllll}\text { Kawada } 1997 & 280 & 432 & 264 & 416 & 15.2 \% & 1.06[0.80,1.40]\end{array}$ $\begin{array}{lllllll}\text { Su 2014 } & 792 & 1294 & 859 & 1288 & 21.0 \% & 0.79[0.67,0.93] \\ \text { Tang 2008 } & 100 & 306 & 138 & 296 & 13.1 \% & 0.56[0.40,077]\end{array}$

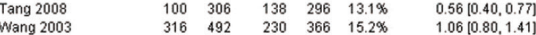
$\begin{array}{lllllll}\text { Wang 2003 } & 316 & 492 & 230 & 366 & 15.2 \% & 1.06[0.80,1.41] \\ \text { Yang 2015 } & 833 & 1366 & 867 & 1306 & 21.2 \% & 0.79[0.68,0.93]\end{array}$ $\begin{array}{lrrrr}\text { Total }(95 \% \mathrm{Cl}) \quad 4270 & 4052 & 100.0 \% & 0.80[0.67,0.94]\end{array}$ Total events $2540 \quad 2620$ Heterogeneity: Taú $=0.03 ; \mathrm{Chi}^{2}=15.58, \mathrm{df}=5(P=0.008) ; \mathrm{I}^{2}=68 \%$

3)

G

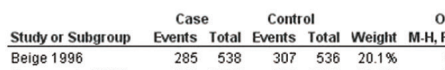
\begin{tabular}{llllll}
\hline Beige 1996 & 285 & 538 & 307 & 536 & $20.1 \%$
\end{tabular} Buraczynska 200 Losito 2002 $\begin{array}{lllll}520 & 190 & 338 & 12.4 \%\end{array}$ Total events $\quad 1483 \quad 1454$ Heterogeneity: Tau $^{2}=0.00 ; \mathrm{Ch}^{2}=0.42, \mathrm{df}=3(\mathrm{P}=0.94) ; \mathrm{P}^{2}=0 \%$ Test for overall effect $Z=3.14(P=0.002)$

I
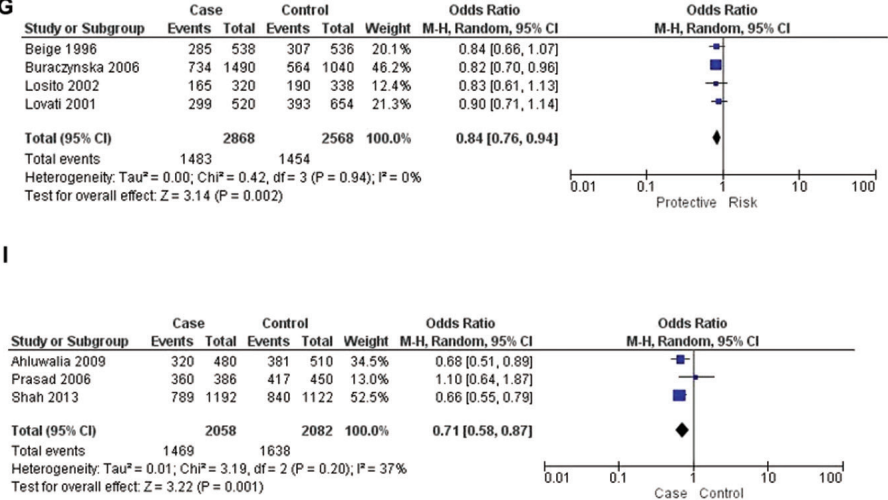

B
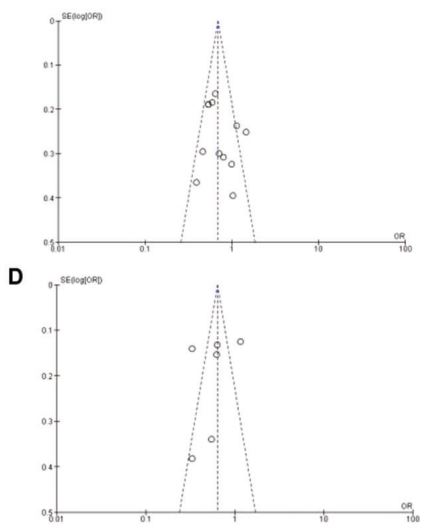

$\mathbf{F}$
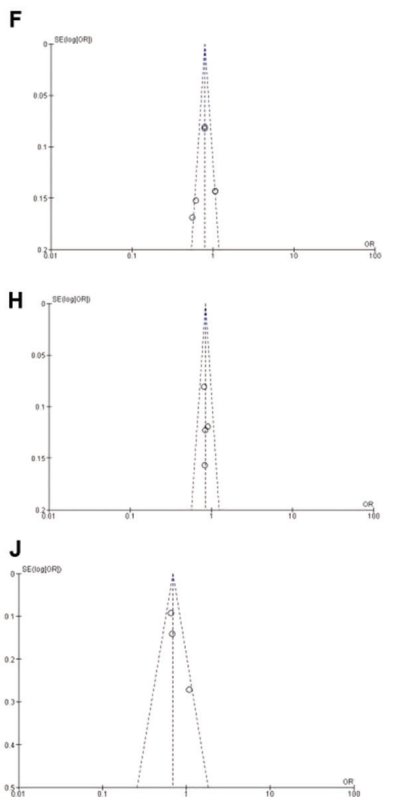

Figure 2 Forest and funnel plots for statistically significant results. (A) Forest plot-ACE insertion/deletion (I/D) investigation, individuals with type 2 diabetic nephropathy compared with individuals with type 2 diabetes mellitus in an East Asian population (ACE insertion compared with deletion). (B) Funnel plot-ACE I/D investigation, individuals with type 2 diabetes and nephropathy compared with individuals with type 2 diabetes mellitus (without nephropathy) in an East Asian population (ACE insertion compared with deletion). (C) Forest plot-ACE I/D investigation, individuals with type 2 diabetes and nephropathy compared with individuals with type 2 diabetes mellitus (without nephropathy) in a South Asian population (ACE insertion compared with deletion). (D) Funnel plot-ACE I/D investigation, individuals with type 2 diabetic nephropathy compared with individuals with type 2 diabetes mellitus in a South Asian population (ACE insertion compared with deletion). (E) Forest plotACE I/D investigation, individuals with end-stage renal disease compared with healthy controls in an East Asian population (ACE insertion compared with deletion). (F) Funnel plot-ACE I/D investigation, individuals with end-stage renal disease compared with healthy controls in an East Asian population (ACE insertion compared with deletion). (G) Forest plot-angiotensinogen (AGT) rs699 investigation, individuals with end-stage renal disease compared with healthy controls in a European population (AGT rs699 T allele compared with C allele). (H) Funnel plot-AGT rs699 investigation, individuals with end-stage renal disease compared with healthy controls in a European population (AGT rs699 T allele compared with C allele). (I) Forest plot-angiotensin II receptor type 1 (AGTR1) rs5186 investigation, individuals with type 2 diabetic nephropathy compared with individuals with type 2 diabetes mellitus in a South Asian population (AGTR1 rs5186 A allele compared with C allele). (J) Funnel plot-AGTR1 rs5186 investigation, individuals with type 2 diabetes and nephropathy compared with individuals with type 2 diabetes mellitus (without nephropathy) in a South Asian population (AGTR1 rs5186 A allele compared with C allele).

polymorphism and the development of DN to ESRD, in that the presence of the deletion was associated with ESRD susceptibility ${ }^{36}$ Despite having differences in the inclusion criteria to our meta-analysis, in that these investigations did not include any article published since $2011^{3536}$ and included individuals with microalbuminuria as cases,${ }^{35}$ we returned similar results to the 2005 previous meta-analysis. Including individuals with microalbuminuria in the control population may cause challenges with phenotype definition as microalbuminuria may regress, remain stable or progress to macroalbuminuria ${ }^{37-39}$ over time. Individuals with microalbuminuria were therefore 
excluded from both case and control definitions to clarify the phenotypes in our review.

In our meta-analysis of $A C E$, which comprised 15265 individuals with CKD and 18474 individuals as controls from 98 population groups, we identified three significant associations of the ACEI/D polymorphism with CKD. Due to previously reported heterogeneity between different ethnic groups, ${ }^{35}$ we included this as a risk factor and performed each analysis per ethnicity (see online supplementary table S2). Despite some of the allele frequency distributions varying across different ethnicities, the direction of the effect was consistent among the different ethnicities: where populations had different minor allele frequencies (MAFs), they often reported similar ORs in the meta-analysis.

First, comparisons between T2DN and T2DM in East Asian and South Asian populations returned significant results highlighting a protective effect of the $A C E$ insertion in the development of $\mathrm{DN}$ ( $\mathrm{p}=0.009$ and $\mathrm{p}=0.01$, respectively). This result was mimicked in the comparison of individuals with ESRD, which was not caused by DN, and healthy control individuals in an East Asian population $(\mathrm{p}=0.008)$. The $A C E \mathrm{I} / \mathrm{D}$ polymorphism remains a well-characterised genetic locus associated with the progression of $\mathrm{DN}$.

AGT encodes the AGT glycoprotein, which is created in the liver and facilitates the creation of angiotensin I. ${ }^{110} \mathrm{It}$ is located on chromosome 1. Several investigations have been conducted into the $A G T$ gene variants and their association with risk of CKD. ${ }^{40-43}$ Among these, Zhou and colleagues undertook a meta-analysis investigation into $A G T$ rs699 and its association with ESRD. ${ }^{40}$ The results of this study are in agreement with ours in relation to the European ethnicity. Our meta-analysis encompassing 5463 individuals with renal disease and 6385 individuals without; the $\mathrm{T}$ allele provided a protective effect in ESRD development $(p=0.002)$ within this European population.

In European and Middle Eastern populations, the allele distribution of rs699 was very similar to the comparison of T2DN versus T2DM, yet different from the East Asian population. This may have had an impact on the results, potentially limiting the robustness of association analyses across ethnicities.

The AGTR1 gene has been shown to be involved in the regulation of blood pressure, fluid and electrolyte balance. ${ }^{11}$ It may also have a role in inflammation and vasoconstriction. ${ }^{44}$ SNP rs5186, an AC nucleotide substitution at position 1166 in the $3^{\prime}$ untranslated region of chromosome 3 , is reportedly able to be recognised by microRNA-155. When the A allele is present at this locus, microRNA-155 is able to undergo complementary base pairing with AGTR1 messenger RNA to suppress translation. However, this is not possible when the alternative $\mathrm{C}$ allele is present, resulting in increased AGTR1 protein levels. ${ }^{45}$ This interplay may affect blood pressure regulation and warrants further investigation. ${ }^{45}$

Previous studies have identified associations between rs5186 in AGTR1 and diseases including coronary artery disease, ${ }^{46}$ systemic lupus erythematosus ${ }^{47}$ and cancer. ${ }^{48}$ Several smaller studies had also been undertaken to assess links between this gene and renal disease. ${ }^{25-54} \mathrm{We}$ conducted this study to provide a clearer understanding of the effect of this SNP on CKD.

This meta-analysis of AGTR1 variants included 3197 individuals with renal disease and 3720 controls investigating rs5186. One significant result was identified: that the presence of an A allele at this locus provided a lower risk of developing T2DN in a South Asian population $(\mathrm{p}=0.001)$.

One meta-analysis published in $2014^{55}$ assessed AGTR1 in individuals with CKD, ESRD, IgA nephropathy or vesicoureteral reflux. This meta-analysis identified that rs5186 was not associated with any of these diseases, which corresponds to the results from our investigation.

The three remaining RAAS genes included in this meta-analysis, ACE2, AGTR2 and REN, have not been researched as extensively as ACE, AGT and AGTR1 for associations with renal disease. Very few articles were identified describing genetic association studies for these genes at the data extraction stage of the analysis, and those that were removed prior to the quantitative analysis stage, mainly due to the inclusion of paediatric individuals or non-human approaches, as outlined in online supplementary figure S1B,E,F. Further research into the ACE2, AGTR2 and REN genes and their polymorphisms should be undertaken to elucidate their role in CKD and ESRD.

Some studies in our search could not be included in quantitative analysis as they lacked information relating to genotype counts and had an unclear measure and definition of albuminuria for both cases and controls, which could constitute a limitation. Results from genome-wide association studies would have strengthened the analysis, but unfortunately they usually only report significant SNPs. Absolute frequencies are not usually reported at individual SNP level for such largescale studies. Publication bias was reported in two of our quantitative analyses, but was not found in the analyses which provided our significant results. Lack of clarity in phenotype definitions, along with unclear descriptions of ethnicities, inherently challenge the use of meta-analyses of different populations as a valid instrument to uncover robust associations. CKD itself has a range of causes including glomerular damage and declining estimated GFR without albuminuria. Other confounding factors such as hypertension and cardiovascular disease, and a lack of prospective follow-up of included individuals, which would ensure phenotypes are robust and stable, may also cause conflicting results.

\section{CONCLUSION}

This meta-analysis of the RAAS pathway genes and their association with renal disease has provided evidence for five significant associations with individually small effect sizes that may cumulatively contribute to dysfunction 
of the RAAS pathway leading to kidney disease. The insertion in $A C E \mathrm{I} / \mathrm{D}$ polymorphism was a protection factor for the development of DN in individuals with type 2 diabetes mellitus from both East and South Asian origin, and for ESRD in an East Asian population. In Europeans, the $\mathrm{T}$ allele of the AGT rs699 conferred a lower risk of ESRD development in healthy population. The A allele in AGTR1 rs5186 acted as a protection factor for renal disease development in South Asian population.

Further study into the specific ethnicities and investigations into a broader range of RAAS-linked genes, or a deeper analysis of them including investigations of more variants, may pinpoint the molecular basis underlying the role of pathway in kidney disease. Network analysis and functional studies enlightening the mechanisms involved ultimately will be required to complete the picture of RAAS variation in renal traits.

Contributors LJS formulated the research plan, conducted the analysis, interpreted the data, drafted and revised the manuscript. MCG and RCC conducted the analysis, interpreted the data and revised the manuscript. APM acquired the funding, interpreted the data, managed the project and revised the manuscript. AM acquired the funding, formulated the research plan, interpreted the data, managed the project and revised the manuscript. All authors read and approved the final manuscript.

Funding This work has been partly funded by the Medical Research Council (Award Reference MC_PC_15025) and the Public Health Agency R\&D Division (Award Reference STL/4760/13). LJS is the recipient of a Northern Ireland Kidney Research Fund Fellowship. MCG is funded by a Science Foundation IrelandDepartment for the Economy (SFI-DfE) Investigator Program Partnership Award (15/IA/3152). RCC is the recipient of a Department for the Economy (DfE) PhD Studentship.

Competing interests None declared.

Patient consent for publication Not required.

Provenance and peer review Not commissioned; externally peer reviewed.

Data sharing statement The data sets generated and/or analysed during the current study are available from the corresponding author on reasonable request.

Open access This is an open access article distributed in accordance with the Creative Commons Attribution 4.0 Unported (CC BY 4.0) license, which permits others to copy, redistribute, remix, transform and build upon this work for any purpose, provided the original work is properly cited, a link to the licence is given, and indication of whether changes were made. See: https://creativecommons.org/ licenses/by/4.0/.

\section{REFERENCES}

1. Levey AS, Coresh J. Chronic kidney disease. Lancet 2012;379:165-80.

2. Glassock RJ, Warnock DG, Delanaye P. The global burden of chronic kidney disease: estimates, variability and pitfalls. Nat Rev Nephrol 2017;13:104-14.

3. Mills KT, Xu Y, Zhang W, et al. A systematic analysis of worldwide population-based data on the global burden of chronic kidney disease in 2010. Kidney Int 2015;88:950-7.

4. Smyth LJ, Duffy S, Maxwell AP, et al. Genetic and epigenetic factors influencing chronic kidney disease. Am J Physiol Renal Physiol 2014;307:F757-F776.

5. Brancati FL, Whelton PK, Randall BL, et al. Risk of end-stage renal disease in diabetes mellitus: a prospective cohort study of men screened for MRFIT. Multiple Risk Factor Intervention Trial. JAMA 1997;278:2069-74.

6. Klag MJ, Whelton PK, Randall BL, et al. Blood pressure and endstage renal disease in men. N Engl J Med 1996;334:13-18.
7. Cowie CC, Port FK, Wolfe RA, et al. Disparities in incidence of diabetic end-stage renal disease according to race and type of diabetes. N Engl J Med 1989;321:1074-9.

8. Mathur R, Dreyer G, Yaqoob MM, et al. Ethnic differences in the progression of chronic kidney disease and risk of death in a UK diabetic population: an observational cohort study. BMJ Open 2018;8:e020145.

9. Velez JC. The importance of the intrarenal renin-angiotensin system. Nat Clin Pract Nephrol 2009;5:89-100.

10. Nishiyama A, Kim-Mitsuyama S. New approaches to blockade of the renin-angiotensin-aldosterone system: overview of regulation of the renin-angiotensin-aldosterone system. J Pharmacol Sci 2010;113:289-91.

11. Remuzzi G, Perico N, Macia M, et al. The role of renin-angiotensinaldosterone system in the progression of chronic kidney disease. Kidney Int 2005;68:S57-S65.

12. Nishiyama A, Kobori H. Independent regulation of reninangiotensin-aldosterone system in the kidney. Clin Exp Nephrol 2018.

13. Carey RM. The intrarenal renin-angiotensin system in hypertension. Adv Chronic Kidney Dis 2015;22:204-10.

14. Zhang F, Liu H, Liu D, et al. Effects of RAAS Inhibitors in Patients with Kidney Disease. Curr Hypertens Rep 2017;19:72.

15. Coll E, Campos B, González-Núñez D, et al. Association between the $\mathrm{A} 1166 \mathrm{C}$ polymorphism of the angiotensin II receptor type 1 and progression of chronic renal insufficiency. J Nephrol 2003;16:357-64.

16. Bermejo S, García CO, Rodríguez E, et al. The renin-angiotensinaldosterone system blockade in patients with advanced diabetic kidney disease. Nefrologia 2018;38:197-206.

17. Yamout H, Lazich I, Bakris GL. Blood pressure, hypertension, RAAS blockade, and drug therapy in diabetic kidney disease. Adv Chronic Kidney Dis 2014;21:281-6.

18. Rahimi Z. The Role of Renin Angiotensin Aldosterone System Genes in Diabetic Nephropathy. Can J Diabetes 2016;40:178-83.

19. Mezzano SA, Ruiz-Ortega M, Egido J. Angiotensin II and renal fibrosis. Hypertension 2001;38(3 Pt 2):635-8.

20. Kelly TN, Raj D, Rahman M, et al. The role of renin-angiotensinaldosterone system genes in the progression of chronic kidney disease: findings from the Chronic Renal Insufficiency Cohort (CRIC) study. Nephrol Dial Transplant 2015;30:1711-8.

21. Ramanathan G, Elumalai R, Periyasamy S, et al. Renin gene rs1464816 polymorphism contributes to chronic kidney disease progression in ADPKD. J Biomed Sci 2016;23:1-7.

22. Kawada N, Moriyama T, Yokoyama K, et al. Renin-angiotensin system component gene polymorphisms in Japanese maintenance haemodialysis patients. Nephrology 1997;3:521-6.

23. Parsa A, Lovett DH, Peden EA, et al. Renin-angiotensin system gene polymorphisms predict the progression to renal insufficiency among Asians with lupus nephritis. Genes Immun 2005;6:217-24.

24. Ozkaya O, Söylemezoğlu O, Gönen S, et al. Renin-angiotensin system gene polymorphisms: association with susceptibility to Henoch-Schonlein purpura and renal involvement. Clin Rheumatol 2006;25:861-5

25. Lau YK, Woo KT, Choong HL, et al. Renin-angiotensin system gene polymorphisms: its impact on IgAN and its progression to endstage renal failure among Chinese in Singapore. Nephron Physiol 2004;97:p1-p8

26. Mtiraoui N, Ezzidi I, Turki A, et al. Renin-angiotensin-aldosterone system genotypes and haplotypes affect the susceptibility to nephropathy in type 2 diabetes patients. J Renin Angiotensin Aldosterone Syst 2011;12:572-80.

27. Stroup DF, Berlin JA, Morton SC, et al. Meta-analysis of observational studies in epidemiology: a proposal for reporting. Meta-analysis Of Observational Studies in Epidemiology (MOOSE) group. JAMA 2000;283:2008-12.

28. International Genome Population [Internet]. Available: www. internationalgenome.org/category/population

29. Higgins JP, Thompson SG, Deeks JJ, et al. Measuring inconsistency in meta-analyses. BMJ 2003;327:557-60.

30. Rieder MJ, Taylor SL, Clark AG, et al. Sequence variation in the human angiotensin converting enzyme. Nat Genet 1999;22:59-62.

31. Moon JY. Recent update of renin-angiotensin-aldosterone system in the pathogenesis of hypertension. Electrolyte Blood Press 2013;11:41-5.

32. Rigat $B$, Hubert $C$, Corvol $P$, et al. PCR detection of the insertion/ deletion polymorphism of the human angiotensin converting enzyme gene (DCP1) (dipeptidyl carboxypeptidase 1). Nucleic Acids Res 1992;20:1433. 
33. Ha SK, S-k H. ACE insertion/deletion polymorphism and diabetic nephropathy: clinical implications of genetic information. J Diabetes Res 2014;2014:1-8.

34. Marre M, Bernadet P, Gallois Y, et al. Relationships between angiotensin I converting enzyme gene polymorphism, plasma levels, and diabetic retinal and renal complications. Diabetes 1994;43:384-8.

35. Ng DP, Tai BC, Koh D, et al. Angiotensin-I converting enzyme insertion/deletion polymorphism and its association with diabetic nephropathy: a meta-analysis of studies reported between 1994 and 2004 and comprising 14,727 subjects. Diabetologia 2005;48:1008-16.

36. Yu ZY, Chen LS, Zhang LC, et al. Meta-analysis of the relationship between ACE I/D gene polymorphism and end-stage renal disease in patients with diabetic nephropathy. Nephrology 2012;17:480-7.

37. Caramori ML, Fioretto P, Mauer M. The need for early predictors of diabetic nephropathy risk: is albumin excretion rate sufficient? Diabetes 2000;49:1399-408.

38. Perkins BA, Ficociello LH, Silva KH, et al. Regression of microalbuminuria in type 1 diabetes. $N$ Engl J Med 2003;348:2285-93.

39. Zelmanovitz T, Gerchman F, Balthazar AP, et al. Diabetic nephropathy. Diabetol Metab Syndr 2009;1:10.

40. Zhou TB, Yin SS, Qin YH. Association of angiotensinogen M235T gene polymorphism with end-stage renal disease risk: a metaanalysis. Mol Biol Rep 2013;40:765-72.

41. Turgut S, Akın F, Akcılar R, et al. Angiotensin converting enzyme I/D, angiotensinogen M235T and AT1-R A/C1166 gene polymorphisms in patients with acromegaly. Mol Biol Rep 2011;38:569-76.

42. Wang YJ, Pan Y. Angiotensinogen gene M235T polymorphism and risk of coronary artery disease: a meta-analysis. Mol Med Rep 2012;6:884-8.

43. Lin R, Lei Y, Yuan Z, et al. Angiotensinogen gene M235T and T174M polymorphisms and susceptibility of pre-eclampsia: a meta-analysis. Ann Hum Genet 2012;76:377-86.

44. Chow BS, Allen TJ. Angiotensin II type 2 receptor (AT2R) in renal and cardiovascular disease. Clin Sci 2016;130:1307-26.
45. Ceolotto G, Papparella I, Bortoluzzi A, et al. Interplay between miR155, AT1R A1166C polymorphism, and AT1R expression in young untreated hypertensives. Am J Hypertens 2011;24:241-6.

46. Duan LJ, Wang XD. Analysis of correlations between coronary heart disease and haplotypes of the angiotensin II receptor type 1 (AGTR1) gene. Genet Mol Res 2016;15.

47. Baniamerian $\mathrm{H}$, Bahrehmand $\mathrm{F}$, Vaisi-Raygani $\mathrm{A}$, et al. Angiotensin type 1 receptor A1166C polymorphism and systemic lupus erythematosus: correlation with cellular immunity and oxidative stress markers. Lupus 2017;26:1534-9.

48. Pringle KG, Delforce SJ, Wang Y, et al. Renin-angiotensin system gene polymorphisms and endometrial cancer. Endocr Connect 2016;5:128-35.

49. Gao J, Yu QL, Fu RG, et al. Lack of Association Between Polymorphisms in AGT and ATR1 and IgA Nephropathy in a Chinese Population. Genet Test Mol Biomarkers 2015;19:710-3.

50. Huang HD, Lin FJ, Li XJ, et al. Genetic polymorphisms of the renin-angiotensin-aldosterone system in Chinese patients with end-stage renal disease secondary to IgA nephropathy. Chin Med J 2010;123:3238-42.

51. Kim SM, Chin HJ, Oh YK, et al. Blood pressure-related genes and the progression of IgA nephropathy. Nephron Clin Pract 2009;113:c3 01-c308.

52. Savage D. Risk of developing diabetic nephropathy is not associated with synergism between the angiotensin II (type 1) receptor C1166 allele and poor glycaemic control. Nephrol Dial Transplant 1999;14:891-4

53. van Ittersum FJ, de Man AM, Thijssen S, et al. Genetic polymorphisms of the renin-angiotensin system and complications of insulin-dependent diabetes mellitus. Nephrol Dial Transplant 2000;15:1000-7.

54. Prasad P, Tiwari AK, Kumar KM, et al. Chronic renal insufficiency among Asian Indians with type 2 diabetes: I. Role of RAAS gene polymorphisms. BMC Med Genet 2006;7:42.

55. Braliou GG, Grigoriadou AM, Kontou PI, et al. The role of genetic polymorphisms of the Renin-Angiotensin System in renal diseases: A meta-analysis. Comput Struct Biotechnol J 2014;10:1-7. 